\title{
Coronavirus and SARS-CoV-2 Pandemic Diseases
}

\author{
Ayhan Güler ${ }^{1 *}$, Ceren Başkan² Belgin Sırıken ${ }^{3}$
}

\section{Abstract}

Coronaviruses which are a large family of viruses lead to upper-respiratory diseases in the especially respiratory system and enteric, hepatic and neurological systems with different severity in human as well as a wide variety of animals. Coronaviruses involved in four genera, and beta-CoVs are the most important group and the most highly pathogenic viruses against humans such as Severe Acute Respiratory Disease (SARS) -CoV-2. SARS-CoV-2 is the third quite pathogenic human coronavirus, and can pass through animals to human or human to human due to capable of cross the species barrier into the human populations. Up to 2 July, 2020, coronavirus cases are 10,720,755 and deaths number are 517,005. Many variety mammalians groups such as pigs, cows, chicken, dogs, cats and human are harbor for CoVs. Among them, especially bats are very important for harbor and enhance the change of interspecies transmission of the viruses. According to SARS-CoV-2 symptoms, it is change to asymptomatic forms to respiratory failure and systemic manifestations such as sepsis, septic shock and multiple organ dysfunctions syndrome. For SARS-CoV-2 inactivation way is by lipid solvents including $75 \%$ of ether, $80 \%$ of ethanol, $75 \%$ of isopropanol, chlorine containing disinfectant, peroxyacetic acid, and chloroform except for chlorhexidine, alkaline $(\mathrm{pH}>12)$ or acidic $(\mathrm{pH}<3)$ conditions, formalin and glutaraldehyde treatments. It is taken community measures against SAR-CoV-2 to control the spread of infection and diseases. To SARS CoV-2, there has been no vaccine and specific anti-viral drugs so far. Therefore, public health measures are considered as an effective tool for community. For this aim, hand hygiene, use of mask, hospital environment, droplet, airborne and contact precautions, institutional safeguard and standard measures should be used.

Keywords: Coronavirus, SARS-CoV-2, structure, symptoms, preventive measure

\section{Introduction}

Viral diseases on going to emerge and cause serious disease in the world. The issue, therefore, a big challenge for public health. In the last two decades, severe acute respiratory coronavirus (SARS-CoV) and H1N1 influenza have been recorded in 2002-2003 and 2009, respectively. In addition, in 2012, Middle East Respiratory Diseases (MERS-CoV) was firstly identified (1). Then, in Wuhan, China, it was seen low respiratory infections detected in 2019 but the agent did not know. After, the etiology of this disease was identified as a novel virus and belonging to $\mathrm{CoV}$ family. The virus was called COVID-19 after soon SARS-CoV-2 (1)

Coronavirus: Generally, coronaviruses lead to diseases in the especially respiratory system and enteric, hepatic and neurological systems with different severity in human as well as a wide variety of animals. Severe Acute Respiratory Disease (SARS) -CoV-2 is the third quite pathogenic human coronavirus, and can pass through animals to human or human to human due to capable of cross the species barrier into the human populations.
The World Health Organization (WHO) reported that SARS-CoV-2 a pandemic and March $(2,3,4)$ Up to 30 June, 2020, coronavirus cases are 10,435,321 and deaths number are 508,844 (5). Coronaviruses involved in four genera; Alfacoronavirus (alfa-CoVs), Betacoronavirus (beta-CoVs or B-CoVs), Gammacoronavirus (gamma-CoVs) and Deltacoranavirus (delta-CoVs). Among four genera, beta$\mathrm{CoVs}$ are the most important group and the most highly pathogenic viruses against humans such as SARS -CoV-2, Middle East respiratory Diseases (MERS)-CoV and SARS$\mathrm{CoV}(6,7,8)$.

Structure: The CoVs has a single stranded and RNA positive polarity genome without segment. The CoVs's virions contain four main structural proteins; these are nucleocapsid (N) protein, which binding CoV's RNA genome and playing a role in the replication of viral RNA host's cellular response, the transmembrane (M) protein, playing a key role as it turns cellular membranes into factories for making new virus particles, the envelope (E) protein, playing three roles-interaction between cytoplasmic tail of $\mathrm{M}$ and $\mathrm{E}$ protein, releasing virions and the virus pathogenesis, and the last one is the spike (S) protein $(9,10)$. (Figure 1). 
Betacoronaviruses are one of four of coronaviruses. It is in the subfamily Orthocoronavirinae in the family Coronaviridae, of the order Nidovirales. They are enveloped, positive-sense, single-stranded RNA, on average, 30 kilobases (Figure 2). The virus possesses zoonotic features. The coronavirus genera are each composed of varying viral lineages with the betacoronavirus genus containing four lineages: A, B, C and $\mathrm{D}$ (Table 1). In older literature, this genus is also known as group 2 coronaviruses (11).

\section{Betacoranavirus (beta-CoVs or B-CoVs)}

Beta-CoVs was classified four subclassifications. The genera were reclassified in 2018 as Embecovirus, Sarbecovirus, Merbecovirus and Nobecovirus (12), previously called lineage A, B, C and D, respectively (13).
After that, the new a fifth subgenus was also included named Hibecovirus (12, (Table 1).

The beta-CoVs of the greatest clinical importance concerning human are OC43 (which can cause the common cold) and HKU1 of the A lineage, SARS-CoV and SARSCoV-2 (which causes the disease COVID-19) of the B lineage (14), and MERS-CoV of the C lineage. MERS$\mathrm{CoV}$ is the first betacoronavirus belonging to lineage $\mathrm{C}$ that is known to infect humans (Table 1) $(15), 16)$.

The characteristic of CoVs can achieve rapid adaptation to new host or different environment conditions due to recombination tendency and inherently high mutation rate $(17,18,20)$..

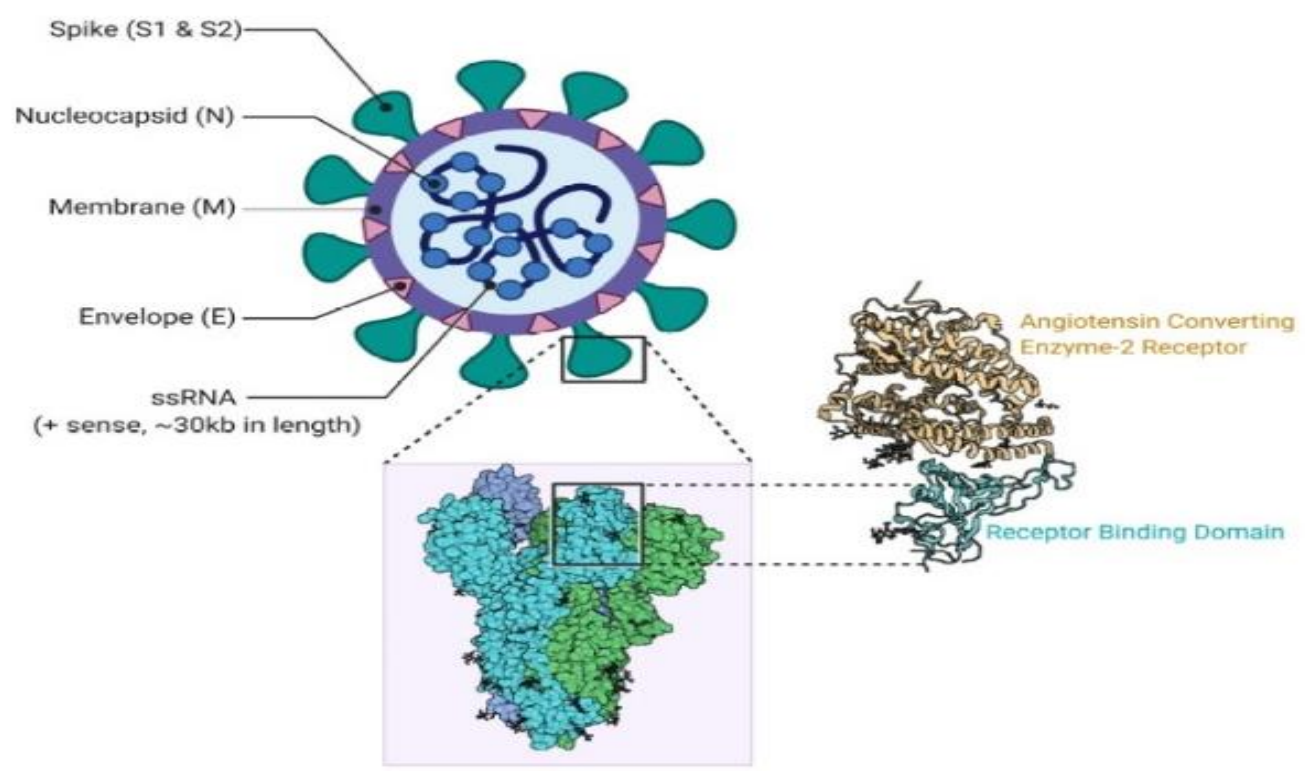

Figure 1. SARS- CoV 2 Structure (Rohan Bir Sing in (1).

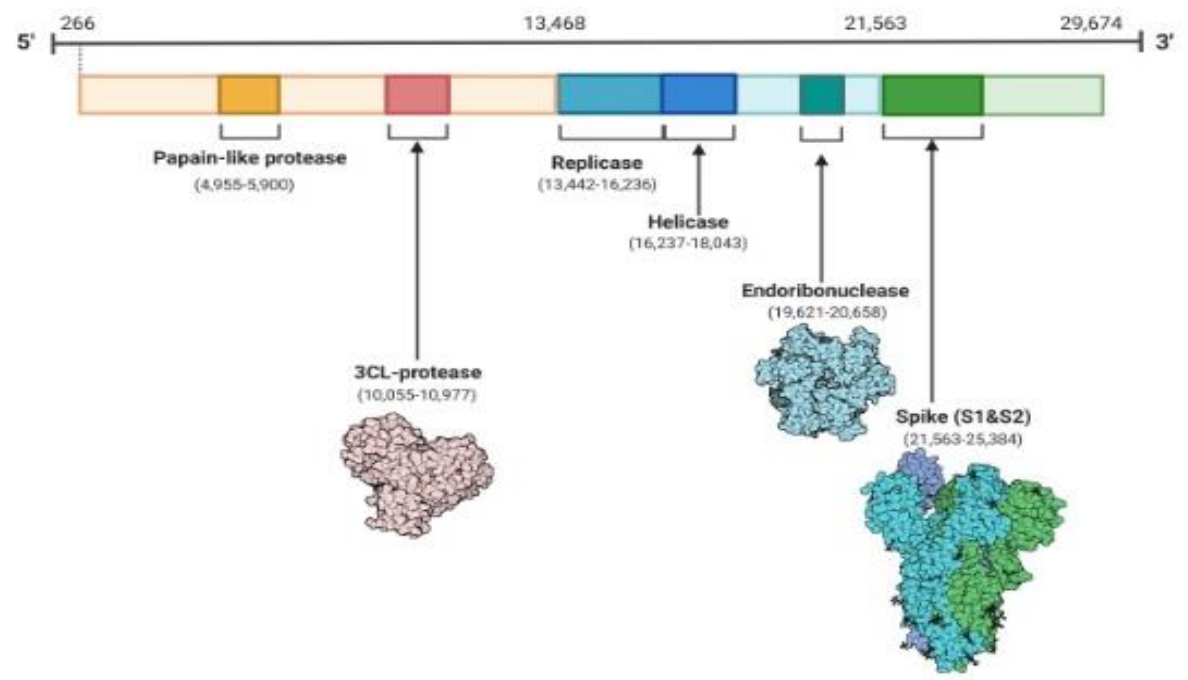

Figure 2. Single-stranded RNA genome of SARS-CoV2 ((Rohan Bir Sing in (1). 
Table 1. Betacoronavirus $(11,12,19)$

\begin{tabular}{|c|c|c|c|c|c|}
\hline Lineage & Lineage A & Lineage B & Lineage C & Lineage D & \\
\hline Subgenus & Embecovirus & Sarbecovirus & Merbecovirus & Nobecovirus & Hibecovirus \\
\hline \multirow[t]{4}{*}{ Example } & $\begin{array}{c}\text { Human } \\
\text { coronavirus } \\
\text { (HCoV-OC43) }\end{array}$ & SARSr-CoV & $\begin{array}{c}\text { Tylonycteris bat } \\
\text { coronavirus }\end{array}$ & $\begin{array}{l}\text { Rousettus bat } \\
\text { coronavirus }\end{array}$ & $\begin{array}{c}\text { Zaria bat } \\
\text { coronavirus }\end{array}$ \\
\hline & HCoV-HKU1 & $\begin{array}{c}\text { (SARS-CoV-2, } \\
\text { SARS-CoV-2 } \\
\text { HKU4 }\end{array}$ & $\begin{array}{c}\text { HKU4 } \\
\text { (BtCoV-HKU4) }\end{array}$ & $\begin{array}{c}\text { HKU9 } \\
\text { (BtCoV-HKU9) }\end{array}$ & $\begin{array}{l}\text { Bat Hp- } \\
\text { betacoronavirus }\end{array}$ \\
\hline & & (BtCoV-HKU4) & $\begin{array}{l}\text { Pipistrellus bat } \\
\text { coronavirus }\end{array}$ & & \\
\hline & $\begin{array}{l}\text { (Various } \\
\text { species) }\end{array}$ & $\begin{array}{c}\text { Bat SL-CoV- } \\
\text { W1V1 }\end{array}$ & $\begin{array}{c}\text { HKU5 } \\
\text { (BtCoV-HKU5) }\end{array}$ & & \\
\hline
\end{tabular}

\section{Human coronaviruses}

Firstly, three human coronaviruses were known to exist: human coronavirus 229E (HCoV-229E), HCoV-OC43 and severe acute respiratory syndrome (SARS)-associated coronavirus (SARS-CoV). Then, it was reported that the identification of a fourth human coronavirus, HCoV-NL63, using a new method of virus discovery (Table 1) (20). However, then, three CoVs have been identified. Nowadays, for human, at least seven coronavirus species are identified as pathogens. Four of these are represent above lines. In addition, the other three human coronaviruses are HCoV-HKU1, MERS-CoV (Middle East respiratory syndrome) and SARS-CoV-2 (CoVID-19). There is variation for pathogenesis among these 7 species. For instance, HCoV-229E, HCoV-OC43, HCoV-NL63 and HCoV-HKU1 lead to only mild upper respiratory disease. They seldom cause to disease for in infants, young children, and elderly people (21). Remaining three species are more dangerous and can cause lower respiratory tract and trigger a severe respiratory condition in humans. SARS-CoV caused outbreak in 2002 and 2003 (22, 2), and responsible for the Middle East respiratory syndrome (MERS-CoV), which emerged in 2012 and remained in the circulation in camels (23). SARS-CoV and MERS-CoV caused quite important concern because they crossed the species barrier and caused severe diseases. SARS-CoV emerged in Asia and spread rapidly to several countries across the world. MERS-CoV has largely been restricted to infections acquired in the Middle East. The two viruses are related to spread from human to human, and death rates are high (24).

\section{Harbour of CoVs}

Many variety mammalians groups such as pigs, cows, chicken, dogs, cats and human are harbor for CoVs. Among them, especially bats are very important for harbor and enhance the change of interspecies transmission of the viruses.

Before the SARS epidemic, bats were not known to be hosts for CoVs. But after the SARS epidemic, there are enhance, and bats have been found to be host of at least 30 CoVs (25).

Bats also recognized to be hosted some others (rabies and other lyssaviruses, Hendra, Nipah and Ebola virus) highly pathogenic viruses. Notable, horseshoe bats (high level) as well as palm civet cats (intermediate level) are considered to be reservoir of SARS-CoVs (26) (Figure 3). According to other subgenus Merbecovirus, which found to be closely related to the MERS-CoV in dromedary camels and humans $(27,28)$.

For beta-CoVs subgenera, so far, Sarbocovirus (SARSrelated CoVs), Merbecovirus (such as MERS-CoVs), Nobecovirus and Hibecovirus have been determined in bats $(12,27,29,30)$.

As a result, in the last 125 years, it has witnessed a large number of novel CoVs, and bats are the largest number of CoVs harbor such as SARS-CoVs and MERS- CoVs (31). Beside beta-CoVs, bats are also harbor for alpha-CoVs. But birds are reservoir for gamma and delta-CoVs (32).

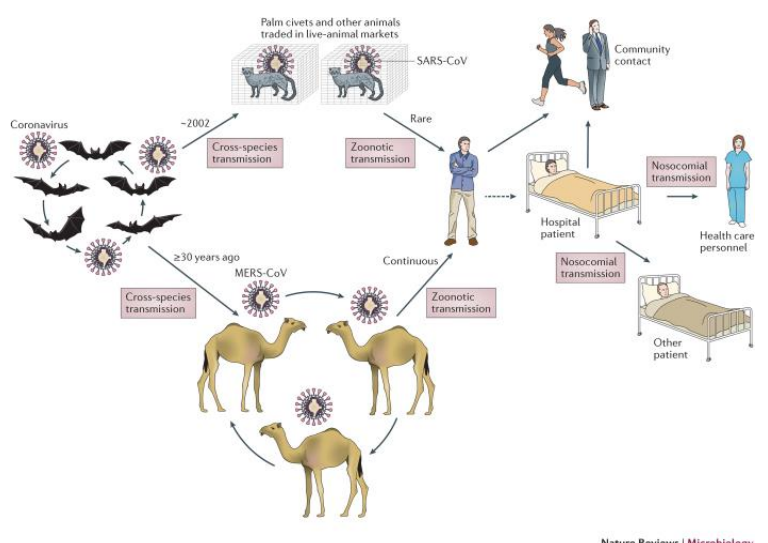

Figure 3. The emergence of SARS-CoV and MERS-CoV (33). 


\section{Severe Acute Respiratory Syndrome Coronavirus (SARS-CoV-2 or COVID-19)}

Severe Acute Respiratory Syndrome Coronavirus (SARSCoV-2 or COVID-19) is the one of coronavirus strain caused coronavirus disease 2019 (COVID-19). The agent is responsible of COVID-19 pandemic. The disease is a contagious and has been seen recently in worldwide. Although most people infected with the virus will experience mild or moderate respiratory illness and healing without requiring special treatment, older people and people with chronic diseases and immunosuppressive problems are more likely to develop quite serious diseases even resulting in death $(4,21)$.

Initially, the 2019-nCoV (Novel Coronavirus Pneumonia NCP) called by the Chinese government causes severely lower respiratory tract diseases and also cause outbreak. The disease, then, was called COVID-19 by World health Organization (4.21) (Figure 4) (34). After that, 2019-nCoV was recalled Severe Acute Respiratory Syndrome Coronavirus (SARS-CoV-2) by the Coronaviridae Study Group of International Committee on Taxonomy of Viruses (35). The virus belongs to Pisuviricetes class, Nidovirales order and Coronaviridae familiy. The agent places the betacoronavirus genus, Sarbecovirus subgenus and severe acute respiratory-related coronavirus species and severe acute respiratory syndrome coronavirus 2 strain (36).
The structure of the viruses has shown in Figure 5 A, B. A genomic structure of SARS-CoV-2 is typical of other betacoronaviruses. It contains 14 open reading frames (ORFs) encoding 27 proteins (37).

According to phylogenetic analysis of the SAES-CoV-2, the virus belongs to different clade from MERS-CoV, and it is highly related to Bat SARS-like coronavirus than SARS-CoV. It is known that Bat SARS like CoV isolated from Chine between 2015 and 2018, and main reservoir is bats $(30,38)$. When genomic compression to SARS, SARSCoV-2 has shown only 380 amino acid substitution, and 27 mutations are observed. Due to these mutation, pathogenicity of SARS-CoV-2 seem lower than SARSCoV (30). The SARS-CoV and MERS-CoV structure and replication have also been showed in Figure 6. (33).

When compared to SARS (reproductive number (R0): 1.71.9), the R0 of the novel infection SARS CoV-2 is estimated by WHO to range between 2 and 2.5. The range is also higher than MERS (R0: $<1)$. The higher R0 indicates that SARS-CoV-2 has a higher pandemic potential $(\mathrm{Wu}$ et al., 2020). However, fatality rate of SARS-CoV-2 (2.3\%) is lower than SARS $(9.5 \%)$ and MERS (34.4\%) (CCDC).

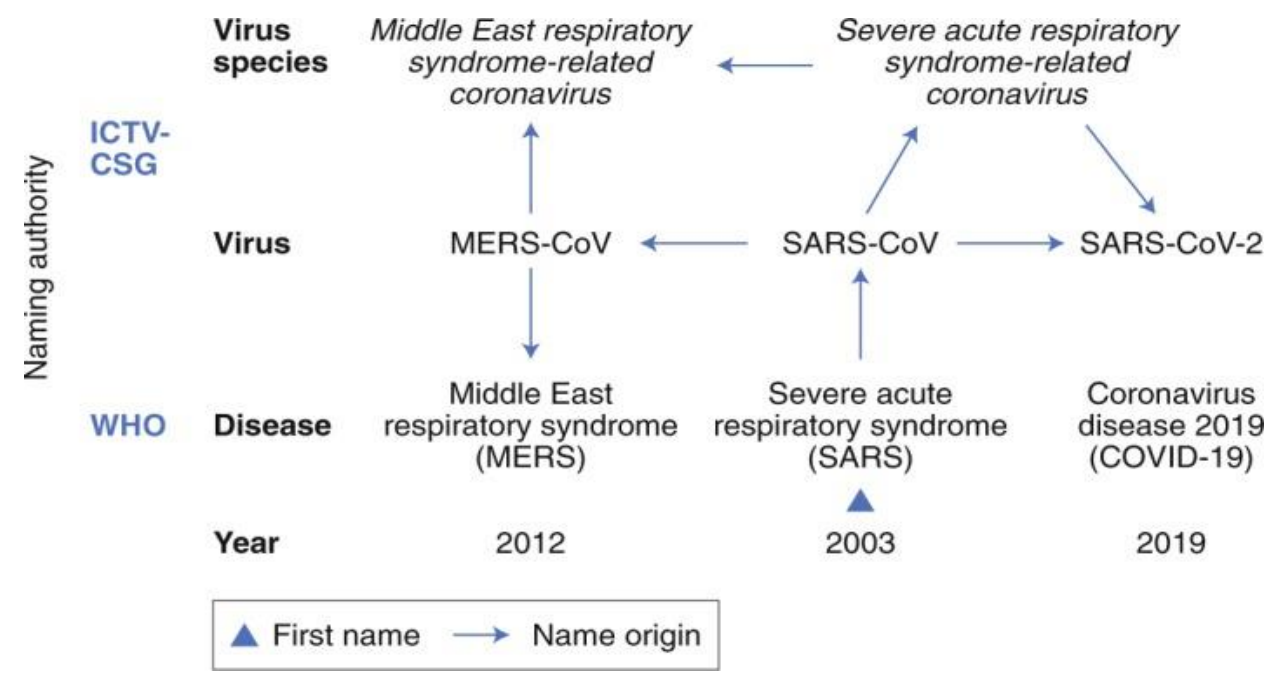

Figure 4. History of coronavirus naming during the three zoonotic outbreaks in relation to virus taxonomy and diseases caused by Coronaviruses (35).

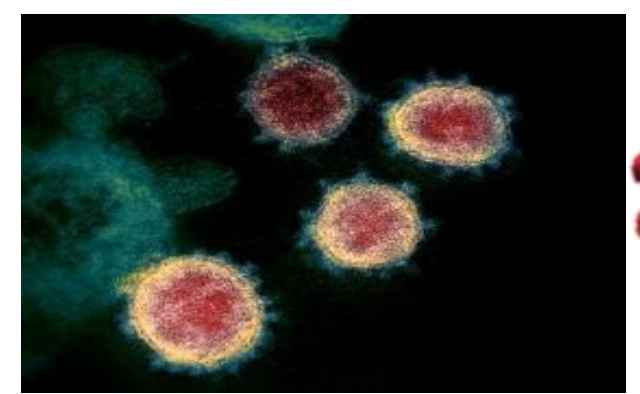

A

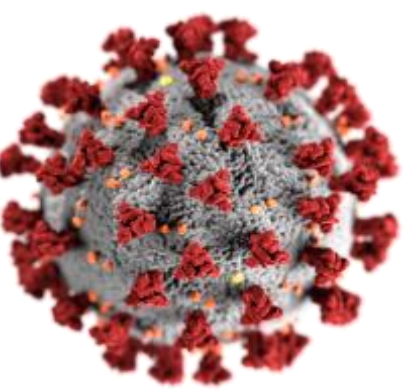

B

Figure 5. A-Electron microscope image of SARS-CoV-2 (Novel Coronavirus SARS-CoV-2- (39,40) B-Illustration of a SARS-CoV-2 virion 


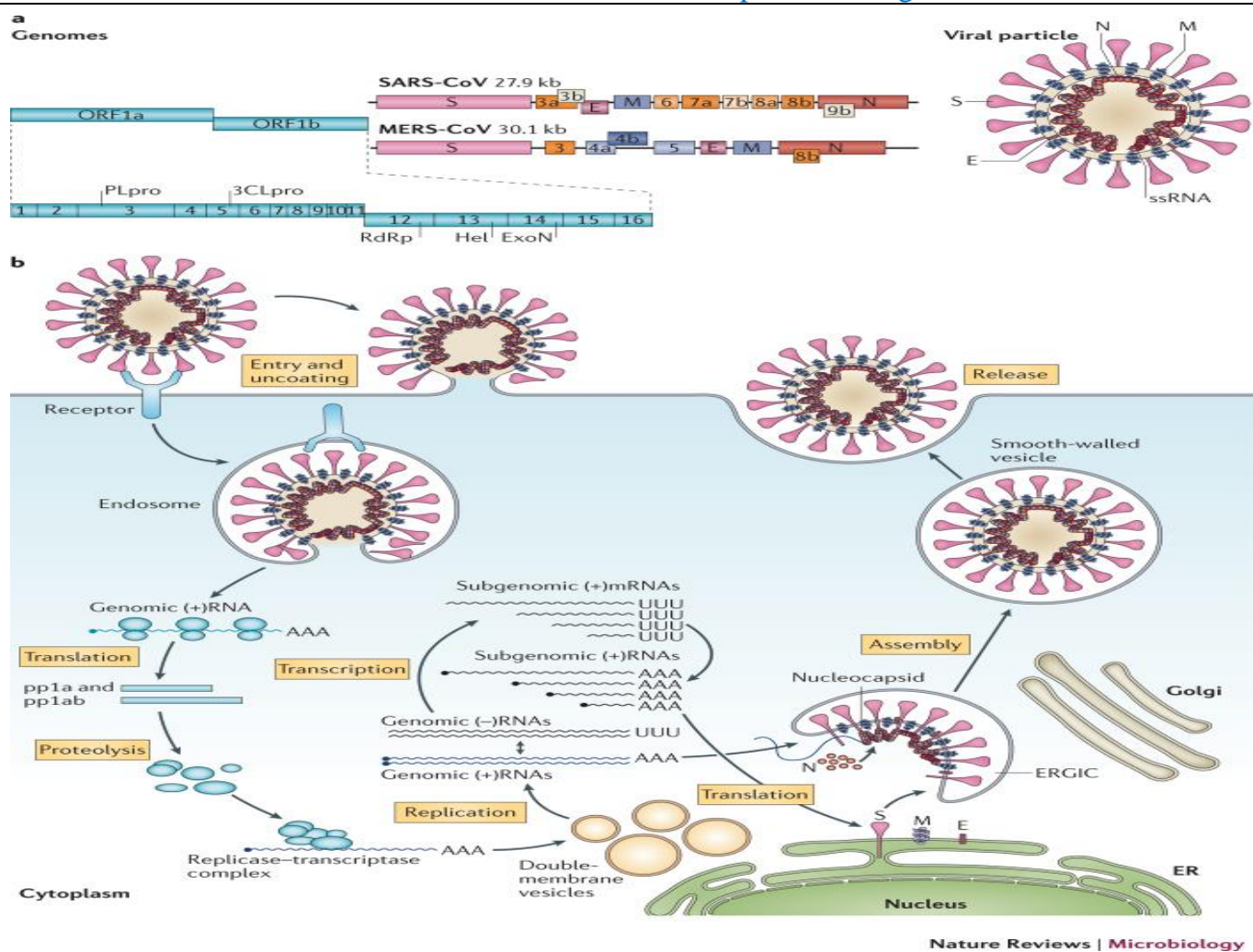

Figure 6. SARS-CoV and MERS-CoV structure and replication (33).

\section{Symptoms}

It is change to asymptomatic forms to respiratory failure and systemic manifestations such as sepsis, septic shock, and multiple organ dysfunctions syndrome. According to SARS-CoV2 symptoms, Huang et al. (2020) reported that fever, malaise, dry cough and dyspnea were seen patients. All cases have shown pneumonia. About third of those required intensive care unit and there were $6(15 \%)$ fatal cases. Another reports, Chine CDC (41) stated that there were $62 \%$ confirmed cases of 72,314 cases, and $1 \%$ of whom was no symptoms, 49 of which with cardiovascular disease, diabetes, chronic respiratory disease, and oncological diseases, died (above 9 years old). According to (30), SARS-CoV-2 symptoms are divided three groups: mild, severe and critical diseases. Mild disease can occur $81 \%$ of cases. In the type, non- pneumonia or mild pneumonia are seen in the patients. The severe disease has shown $14 \%$ of cases. The symptoms are dyspnea, respiratory frequency ( $\geqslant 30 /$ minute) and needed ventilation with oxygen due to low blood oxygen saturation. Critical disease has seen $5 \%$ of cases. Respiratory failure, septic shock, and or multiple organ dysfunction or failure are seen in the cases with COVID-19.

According to (1), there are 3 types of symptoms may observe in patients with COVID-19 (1),

These are;

1) Mild illness form: It is seen upper respiratory tract viral infections like mild fever, cough /dry form), sore throat, nasal congestion, malaise, headache and muscle pain, loss of smell taste, diarrhea, and vomiting. In more serious patient, it is also seen dyspnea.
2) Moderate pneumonia form: It is seen respiratory symptoms like cough and shortness of breath as symptoms.

3) Acute Respiratory Distress Syndrome (ARDS) form: It is seen failure of respiratory system or worsening of respiratory picture. It is seen also sepsis.

\section{Inactivation of SARS CoV-2}

The virus sensitive to ultraviolet light at $254 \mathrm{~nm}$ and heat treatment $\left(65^{\circ} \mathrm{C}\right.$ or higher). Another inactivation way is by lipid solvents including $75 \%$ of ether, $80 \%$ of ethanol, $75 \%$ of isopropanol, chlorine containing disinfectant, peroxyacetic acid, and chloroform except for chlorhexidine, alkaline $(\mathrm{pH}>12)$ or acidic $(\mathrm{pH}<3)$ conditions, formalin and glutaraldehyde treatments $(42,43,44,45)$. According to (46), ethanol and 2-propanol of $\geqslant 30 \% \quad(\mathrm{vol} / \mathrm{vol})$ concentration were efficient in inactivating the virus in 30 s. For virus inactivation, it needed biosafety 3 level (BSL 3) (47).

The number of Coronavirus cases and death in the some of the country

According to (5), up to 2 July, 2020, coronavirus cases are $10,720,755$ and deaths number are 517,005 . The number of cases according to country; In the United State, it has been seen 2,763,681 confirmed cases and 130,570 death, and the number is the highest number of confirmed coronavirus cases. Brazil is second range, and the number of SARS CoV-2 cases is $1,426,913$ cases. A total COVID-19 number are 60,194 deaths, and China with 83, 534 cases and 4,634 death, England with 313,483 and 43,906 death, Germany with 196,296 and 9,059 deaths, Iran with 230,211 cases and 10,958 deaths, Spain with 296,739 cases and 28,363 deaths, 
Italy with 240,760 cases and 34,788 death, Pakistan with 213,470 cases and 4,395 deaths, France with 165,719 cases and 29,861 deaths, Canada with 104,271 cases and 8,615 deaths, Sweden with 69,692 cases and 5,370 deaths, Netherlands with 50,273 cases and 6,113 deaths,. In Turkey, 5,150 death and 201,098 cases are seen.

\section{Preventive measure of SARS CoV-2}

It must be taken community measures against SAR-CoV-2 to control the spread of infection and diseases. To SARS CoV-2, there has been no vaccine and specific anti-viral drugs so far. Therefore, public health measures are considered as an effective tool for community. For this aim, it must use hand hygiene, use of mask, hospital environment, droplet, airborne and contact precautions, institutional safeguard and standard measures.

The most important measure to control the spread of COVID-19 infection is hand wash frequently with soap and water or with an alcohol-based hand sanitizer. If hands are not visibly dirty, they should preferably have washed with alcohol-based sanitizer for at least 20 to 30 seconds (48). But, if hand dirty, they should wash with soap and water for 40-60 seconds. It must be avoided to contracting person or other people, and hand must not contact eye or mount like that mucosa. Susceptible or infected surfaces and other surfaces must be clean with appropriate disinfection technique with $1.0 \%$ hypochlorite solution or $70.0 \%$ alcohol to limit the spread of infection To prevent of infection spread by aerosol or droplet infection, it must be mandatorily using mask. In the hospital, it is mandatory wear surgical mask. As air-droplet seldom crosses beyond 1 meter, within 1 meter between health and infected people, all health care workers must wear medical/ surgical mask along with face shield or goggles to protect eye from accidental spiting from patients. Personal protective equipment such as masks, gloves, gown, and goggles are necessary to prevent infection to health care workers. Dedicated instruments like stethoscope and thermometer) should be used for each patient however in case of sharing each instrument must be disinfected with alcohol or hypochlorite solution. Health care worker must avoid touching their mouth, nose or eye, frequent hand wash (21).

\section{Conclusion}

Severe Acute Respiratory Disease (SARS) $-\mathrm{CoV}-2$ is the third quite pathogenic human coronavirus, and can pass through animals to human or human to human due to capable of cross the species barrier into the human populations. Up to 2 July, 2020, coronavirus cases are $10,720,755$ and deaths number are 517,005. Many variety mammalians groups such as pigs, cows, chicken, dogs, cats and human are harbor for CoVs. Among them, especially bats are very important for harbor and enhance the change of interspecies transmission of the viruses. According to SARS-CoV-2 symptoms, it is change to asymptomatic forms to respiratory failure and systemic manifestations such as sepsis, septic shock and multiple organ dysfunctions syndrome. For SARS-CoV-2 inactivation way, it is treatment by using lipid solvent including $75 \%$ of ether, $80 \%$ of ethanol, $75 \%$ of isopropanol, chlorine containing disinfectant, peroxyacetic acid, and chloroform except for chlorhexidine, alkaline $(\mathrm{pH}>12)$ or acidic $(\mathrm{pH}$ $<3$ ) conditions, formalin and glutaraldehyde treatments. It is taken community measures against SAR-CoV-2 to control the spread of infection and diseases. To SARS $\mathrm{CoV}-2$, there has been no vaccine and specific anti-viral drugs so far. Therefore, public health measures are considered as an effective tool for community. For this aim, hand hygiene, use of mask, hospital environment, droplet, airborne and contact precautions, institutional safeguard and standard measures should be used.

\section{Acknowledgment: None}

Conflict of Interest: The authors declare no potential conflicts of interest with respect to the research, authorship, and/or publication of this article.

Author Contributions: AG, CB, BS: Review of the literature, data collection and analyzes AG; Writing and Revisions

Ethical issues: All authors declare originality and ethical approval of research. Responsibilities of research, responsibilities against local ethics commission are under the authors responsibilities. The study was conducted under defined rules by the local ethics commission guidelines and audits.

\section{References}

1. Cascella M, Rajnik M, Cuomo A, Dulebohn SC, Di Napoli R. Features, Evaluation and Treatment Coronavirus (COVID-19). 2020.https://www.ncbi.nlm.nih.gov/books/NBK554776/.

2. Drosten C., Günter S., Preiser W., van der Werf S., Brodt HR., Becker S., et al. Identification of a novel coronavirus in patients with severe acute respiratory syndrome. N. Eng. J. med. 2003. 348: 196776.

3. Lai C-C., Shih,T-P., Ko, W-C., Tang, H-J., Hsueh P-R. Severe acute respiratory syndrome coronavirus 2 (SARS-CoV-2) and coronavirus disease-2010 (COVID-10).: the epidemic and the challenges. Int $\mathbf{J}$ Antimicrobe Agents. 55: 105924.

4. WHO Director-General's opening remarks at the media briefing on COVID-19: 11 March 2020. www.who.int./dg/speeches/detail/whodirector-general-s-opening-remarks-at-the-öedia-briefing-on -covid19-11-march-2020.

5. Worldometer.

Coronavirus/Countries. https://www.worldometers.info/ coronavirus/ countries -wherecoronavirus-has-spread/. Accesed 02.07.2020.

6. Su S, Wong G, Shi W, Liu J, Lai ACK, Zhou J, Liu W, Bi Y, Gao GF. Epidemiology, genetic recombination, and pathogenesis of $\begin{array}{llll}\text { coronaviruses. } & \text { Trends } & \text { Microbiol } 24: 490 & -502 \text {. }\end{array}$ https://doi.org/10.1016/j.tim.2016.03.003.

7. Forni D, Cagliani R, Clerici M, Sironi M. Molecular evolution of human coronavirus genomes. Trends Microbiol.2017. 25:35- 48. https://doi .org/10.1016/j.tim.

8. Cui J, Li F, Shi ZL. Origin and evolution of pathogenic coronaviruses. Nat Rev Microbiol. 17:181-192. 2019. https://doi.org/10.1038/s41579-018-0118-9.

9. Perlman S., Netland J. Coronaviruses post-SARS: update on replication and pathogenesis. Nature Reviews Microbiology,2009. 7(6): 439-450.

10. Schoeman, D., Fielding, B.C. Coronavirus envelope protein: Current knowledge. Virology Journal, 2019. 16 (69): 2-22. 
11. ECDC (European Centre for Diseases Prevention and Control) Rapid Risk Assessment - Severe respiratory disease associated with a novel coronavirus" , 2014.

12. ICTV Taxonomy History:Orthocoronavirinae;, July 2019.

13. de Groot, R. J., Baker, S. C., Baric, R. S., Brown, C. S., Drosten, C., Enjuanes, L., ... \& Perlman, S. Commentary: Middle east respiratory syndrome coronavirus (mers-cov): announcement of the coronavirus study group. Journal of virology, 2013.87(14), 7790-7792.

14. Bedford T., Hodcroft T. "Phylogeny of SARS-like betacoronaviruses". Nextstrain. 2020 https://nextstrain.org/groups/blab/sars-like-cov.

15. Memish Z.A., Zumla, A.I., Al-Hakeem, R.F., Al-Rabeeah, A.A., et al. Family Cluster of Middle East Respiratory Syndrome Coronavirus Infections. New England Journal of Medicine,2013. 368: 2487-2494.

16. ProMed International Society for Infectious Diseases. Donate to support ProMed's coverage of the COVID-19 outbreak. https://promedmail.org. Access date 22.06.2020.

17. Holmes, Edward C., and Andrew Rambaut. "Viral evolution and the emergence of SARS coronavirus." Philosophical Transactions of the Royal Society of London. Series B: Biological Sciences,2004.359.1447:1059-1065.

18. Decaro, Nicola, et al. Genetic analysis of canine parvovirus type $2 \mathrm{c}$. Virology, 2009, 385.1: 5-10.

19. NCBI (National Center for Biotechnology Information). Lineage Betacoronavirus.

Ncbi.nlm.nih.gov/Taxonomy/Browser/wwwtax.cgi?id=694002.

Access date 23.06.2020b.

20. Van Der Hoek, Lia, et al. Identification of a new human coronavirus. Nature medicine, 2004, 10.4: 368-373.

21. WHO (World Health Organization). Coronavirus disease 2019 (COVID-19), situation report - 35. https://www.who.int/docs/default-source/coronaviruse/ situationreports/20200224-sitrep-35-covid-19.pdf?sfvrsn1ac4218d_2. Accesed 18.06.2020c

22. Zhong, N. S., Zheng, B. J., Li, Y. M., Poon, L. L. M., Xie, Z. H., Chan, K. H., ... \& Liu, X. Q. (2003). Epidemiology and cause of severe acute respiratory syndrome (SARS) in Guangdong, People's Republic of China, in February, 2003. The Lancet, 362(9393), 13531358.

23. Zaki AM, Van Boheemen S, Bestebroer TM, Osterhaus A, Fouchier R. 2012. Isolation of a novel coronavirus from a man with pneumonia in Saudi Arabia. N Engl J Med 367:1814 -1820. https://doi.org/10.1056/ NEJMoa1211721

24. Sutton TC., Subbarao K. Development of animal models against emerging coronavirus: from SARS to MERS coronavirus. Virology,2015. 479-480: 247-258.

25. Lau, C., Anitole, K., Hodes, C., Lai, D., Pfahles-Hutchens, A., \& Seed, J. Perfluoroalkyl acids: a review of monitoring and toxicological findings. Toxicological sciences, 2007. 99(2), 366-394.

26. Rihtarič, D., Hostnik, P., Steyer, A., Grom, J., \& Toplak, I. Identification of SARS-like coronaviruses in horseshoe bats (Rhinolophus hipposideros) in Slovenia. Archives of virology, 2010. 155(4), 507-514.

27. Corman, V. M., Ithete, N. L., Richards, L. R., Schoeman, M. C., Preiser, W., Drosten, C., \& Drexler, J. F. Rooting the phylogenetic tree of middle East respiratory syndrome coronavirus by characterization of a conspecific virus from an African bat. Journal of virology, 2014. 88(19), 11297-11303.
28. Sabir, J. S., Lam, T. T. Y., Ahmed, M. M., Li, L., Shen, Y., AboAba, S. E., ... \& Alharbi, N. S. Co-circulation of three camel coronavirus species and recombination of MERS-CoVs in Saudi Arabia. Science, 2016. 351(6268), 81-84.

29. Lau, J. T., Gu, J., Tsui, H. Y., \& Wang, Z. Prevalence and associated factors of intention to participate in HIV voluntary counseling and testing for the first time among men who have sex with men in Hong Kong, China. Preventive medicine, 2013. 57(6), 813-818.

30. Wu, Z., \& McGoogan, J. M. Characteristics of and important lessons from the coronavirus disease 2019 (COVID-19) outbreak in China: summary of a report of 72314 cases from the Chinese Center for Disease Control and Prevention. Jama, 2020.323(13), 1239-1242.

31. Wong, A.C.P., Li,X., Lau, S.K.P., Woo, P.C.Y. Global Epidemiology of bat Coronaviruses. Viruses, 2019. 11: 174 (1-17)

32. Woo, P. C., Lau, S. K., Lam, C. S., Lau, C. C., Tsang, A. K., Lau, J. H., ... \& Zheng, B. J. Discovery of seven novel Mammalian and avian coronaviruses in the genus deltacoronavirus supports bat coronaviruses as the gene source of alphacoronavirus and betacoronavirus and avian coronaviruses as the gene source of gammacoronavirus and deltacoronavirus. Journal of virology, 2012. 86(7), 3995-4008.

33. De Wit, E., Van Doremalen, N., Falzarano, D., \& Munster, V. J. SARS and MERS: recent insights into emerging coronaviruses. Nature Reviews Microbiology, 2016. 14(8), 523.

34. Yuen, K-S., Ye, WY., Fung, S-Y., Chan, C-P., Jin, D-Y. SARSCoV-2 and COVID-19: The most important research questions. Cell \& Bioscience, 2020. 10:40.

35. WHO. WHO releases new International Classification of Diseases (ICD 11).2018. https://www.who.int/news-room/detail/18-06-2018who-releases-new-international-classification-of-diseases-(icd-11).

36. Coronaviridae Study Group (CSB) of the International Committee on Taxonomy of Viruses. The species Severe acute respiratory syndrome-related coronavirus: classifying 2019-nCoV and naming it SARS-CoV-2. Nature Microbiology, 2020. 5(4): 536-544.

37. Malik Y.S., Sircar S., Bhat S., Sharun K., Dhama K., Dadar M., et al Emerging novel Coronavirus (2019-nCoV)-current scenario, evolutionary perspective based on genome analysis and recent developments. 2020. Vet Q. 40: 68-76.

38. Lu R., ZhaoX., Li J., Niu P., Yang B., Wu H., et al. Genomic characterization and epidemiology of 2019 novel coronavirus: implications for virus origins and receptor binding. Lancet, 2020 395: 565-574.

39. https://www.flickr.com/photos/niaid/49534865371/

40. https://en.wikipedia.org/wiki/Severe_acute_respiratory_syndrome_c oronavirus_2\#/media/File:SARS-CoV-2_without_background.png.

41. CCDC (Chinese Centre for Diseases Control and Preventation) 2020. The epidemiological characteristics of an outbreak of 2019 novel coronavirus diseases (COVID-19)-China, 2020. China CDC Wkly. 8: 113-122.

42. Rabenau, H. F., J. Cinatl, and H. W. Doerr. "Preliminary Pages." Prions. Vol. 11. Karger Publishers, 2004. I-XI.

43. Suchomel M, Kumdi M, Allegranzi B, Pittet D, Rotter ML. Testing of the world Health Organisation-recommended formulations for surgical hand preparation and proposals for increased efficacy. $\mathbf{J}$ Hosp Infect, 2011. 79: 115-118.

44. Van Doremalen, N., Bushmaker, T., Morris, D. H., Holbrook, M. G. Gamble, A., Williamson, B. N., ... \& Lloyd-Smith, J. O. Aerosol and surface stability of SARS-CoV-2 as compared with SARS-CoV-1. New England Journal of Medicine, 2020. 382(16), 1564-1567. 
45. Ong, S. W. X., Tan, Y. K., Chia, P. Y., Lee, T. H., Ng, O. T., Wong, M. S. Y., \& Marimuthu, K. Air, surface environmental, and personal protective equipment contamination by severe acute respiratory syndrome coronavirus 2 (SARS-CoV-2) from a symptomatic patient. Jama, 2020. 323(16), 1610-1612.

46. Kratzel, A., Todt, D., V'kovski, P., Steiner, S., Gultom, M., Thao, T. T. N., ... \& Dijkman, R. Inactivation of severe acute respiratory syndrome coronavirus 2 by WHO-recommended hand rub formulations and alcohols. Emerging infectious diseases, 2020. 26(7), 1592 .
47. Darnell, MER., Subbarao K., Feinstone SM., Taylor DR Inactivation of coronavirus that induces severe acute respiratory syndrome, SARS-CoV. J Virological Methods, 2004. 121: 85-91.

48. Siddharta, A., Pfaender, S., Vielle, N. J., Dijkman, R., Friesland, M., Becker, B., ... \& Brill, F. H. Virucidal activity of World Health Organization-recommended formulations against enveloped viruses, including zika, ebola, and emerging coronaviruses. The Journal of infectious diseases, 2017. 215(6), 902-906.

Copyright (c) 2020 The Author(s); This is an open-access article distributed under the terms of the Creative Commons Attribution License (http://creativecommons.org/licenses/by/4.0), (CC BY NC) which permits unrestricted use, distribution, and reproduction in any medium, provided the original work is properly cited. International journal of Medical Science and Discovery. 